\title{
Fractographic Evaluation of Medium Carbon Steels with Low Hot Ductility.
}

O. Dremailova, D. Emadi, E. Essadiqi and J. R. Brown

Materials Technology Laboratory, CANMET, Ottawa, Ontario, K1A 0G1

Many steel companies incorporate electric arc furnace methods in steel production, which involves the recycling of steel scrap. Of concern is the effect of increasing level of residual elements such as $\mathrm{Cu}$ and $\mathrm{Sn}$ on the properties of the steel at various stages of production. $[1,2]$ This work examines the effect of these key residuals on the cracking susceptibility during continuous casting by conducting simulation tests using the Gleeble 2000.

Medium carbon $(0.2 \% \mathrm{C})$ steels with various levels of $\mathrm{Sn}$ and constant $\mathrm{Cu}$ and $\mathrm{Ni}$ levels were cast in a vacuum induction furnace then reheated and rolled at CANMET. Samples were machined from these steels for subsequent hot ductility tests in the Gleeble. Testing consisted of performing in-situ melting and solidification in the Gleeble followed by controlled cooling to various temperatures and subsequent tensile testing to fracture to generate hot ductility curves. Optical metallography, scanning electron microscopy with energy dispersive analysis and electron probe microanalysis were carried out to provide microstructural data to assist in the interpretation of the observed variations in ductility. A limited number of tests were interrupted at maximum load and quenched for subsequent Auger scanning electron microscopy. Figure 1 presents the hot ductility curves for each of the steels revealing minimum ductility at $750{ }^{\circ} \mathrm{C}$. The intergranular morphology observed for the plain carbon steel at this temperature is presented in Figure 2 with higher magnification image given in Figure 3. All steels fractured between 700 and $800^{\circ} \mathrm{C}$ were examined in the SEM and exhibited the same failure morphology, which was typically intergranular with a local ductile fracture appearance in the form of microvoid coalescence on the intergranular facets. SEM with energy dispersive X-ray analysis of polished sections close to the fracture revealed the presence of manganese sulfide particles on the prior austenite grain boundaries. These particles were also observed in the microvoids on the fracture surface as shown in Figure 4. The base steel samples quenched from 700 to $800^{\circ} \mathrm{C}$ contained proeutectoid ferrite, as presented in Figure 5.

The observed results for the plain carbon steel can be explained in terms of the presence of grain boundary ferrite and manganese sulfide precipitates. The deterioration in ductility with increasing Sn was found to be associated with $\mathrm{Sn}$ segregation to grain boundaries in agreement with previously reported work. [3]

\section{References}

[1] S. Yue, J.J. Jonas and B. Mintz, "Relationship between hot ductility and cracking during the continuous casting of steel", 13th PTD Conference Proceedings, Vol.13, Iron and Steel Society, 1995, pp. 45-52.

[2] C. Nagasaki and J. Kihara, ISIJ International, Vol. 37, No. 5, 1997, pp. 523-530.

[3] H. Matsuoka et al., "Influence of $\mathrm{Cu}$ and $\mathrm{Sn}$ in hot ductility of steels with various carbon content”, ISIJ International, Vol. 37, No. 3, 1997, pp. 255-262.

[4] This work was part of American Iron and Steel Institute Project 9705 jointly funded by US Department of Energy and AISI participating steel companies. 


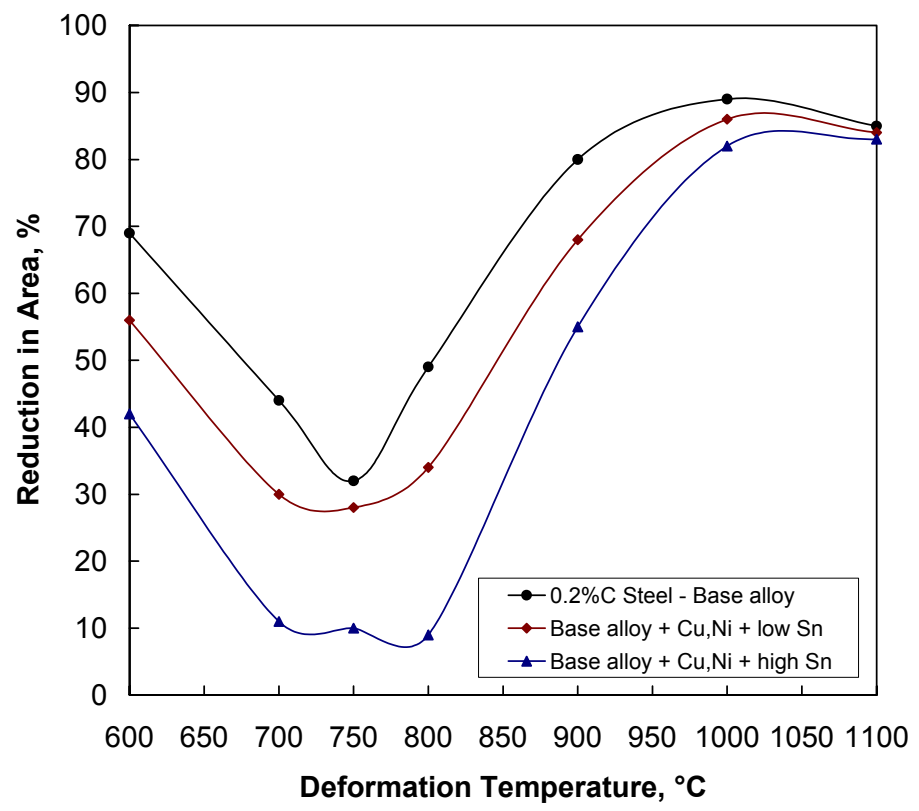

FIG. 1. Hot ductility curves of medium carbon steels.

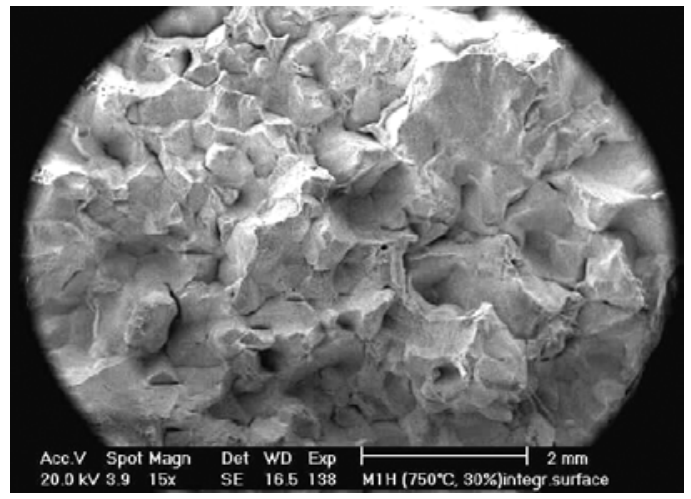

FIG. 2. Fracture surface of plain carbon steel at minimum ductility temperature.

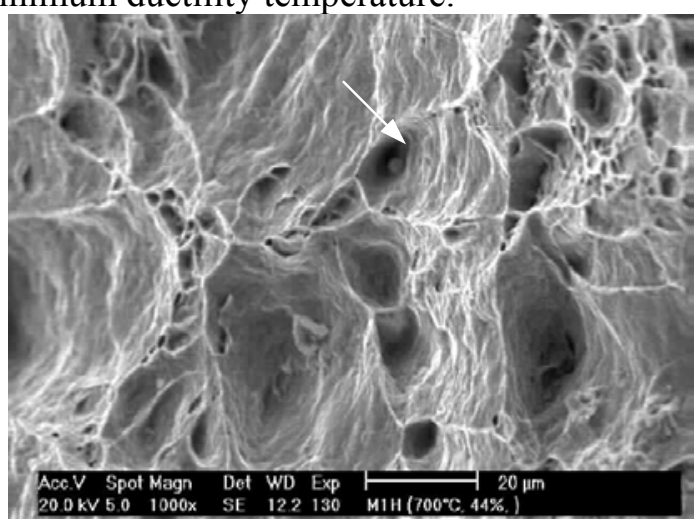

FIG. 4. SEM image of plain carbon steel showing a $\mathrm{MnS}$ particle in a void.

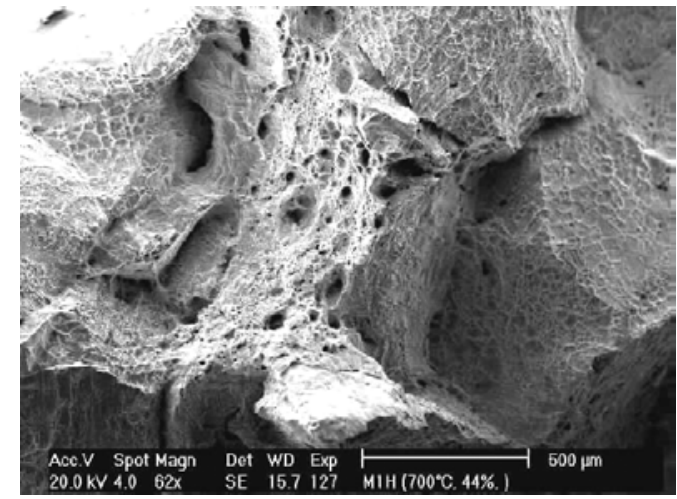

FIG. 3. Fracture surface showing intergranular facets with microvoid coalescence.

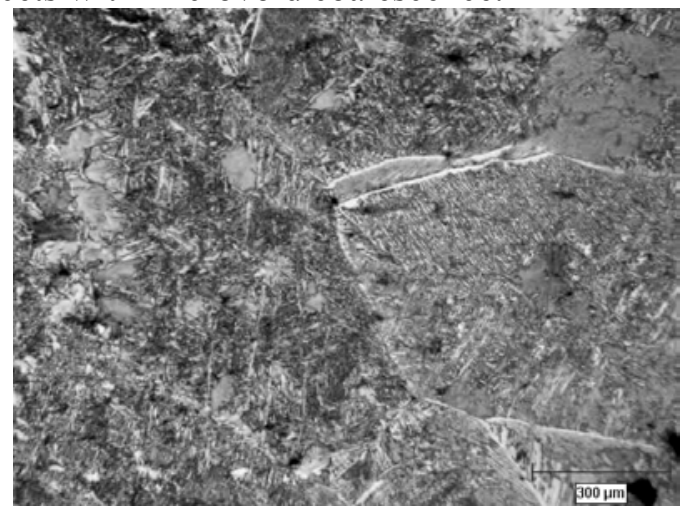

FIG. 5. Quenched sample of plain carbon steel revealing proeutectoid ferrite along the grain boundaries at minimum ductility. 